\title{
Histiocytosis Syndromes of Childhood: A report of four cases
}

\author{
Ramesh $\mathbf{M}^{1}$, Singh $\mathbf{V}^{2}$, Ghuliani $\mathbf{R}^{3}$, Kapur $\mathrm{BN}^{4}$, Singh $\mathbf{J}^{5}$, Shankar $\mathbf{S}^{6}$ \\ ${ }^{1}$ Dr. Midhun Ramesh MBBS, Resident, Dept of Paediatrics, ${ }^{2}$ Dr.Veena Singh MBBS, Resident, Dept of Paediatrics, \\ Armed Forces Medical College, Pune, Maharashtra, India, ${ }^{3} \mathrm{Col}$.(Dr) Ranjit Ghuliani, MBBS, MD (Ped), Sr.Advisor, Dept \\ of Paediatrics, ${ }^{4} \mathrm{Col}$. (Dr) Bhupendra Nath Kapur, MBBS, MD(Med), Sr. Advisor, Dept of Medicine \& Oncology, ${ }^{5}$ Lt. Col. \\ (Dr) Jasjit Singh, MBBS, MD(Med), Classified Specialist, Dept of Medicine, Clinical Hematology \& Oncology, Command \\ Hospital, Southern Command, Pune, Maharashtra, India, ${ }^{6}$ Grp. Capt. (Dr) Subramanian Shankar MBBS, MD(Med), \\ DNB, MNAMS, Fellowship Immunology, Reader, Dept of Medicine, Armed Forces Medical College, Pune, Maharashtra, \\ India.
}

Address for Correspondence: Col.(Dr) R. Ghuliani, E-mail: rghuliani@gmail.com

\begin{abstract}
Histiocytosis Syndromes of Childhood (HSC) are a group of rare and diverse disorders characterized by aggressive proliferation or accumulation of cells of monocyte - macrophage system of bone marrow. The clinical spectrum of this syndrome is distinctly varied. The exact pathophysiology of HSC is yet to be determined; however, evidence suggests that one of the subtypes, Hemophagocytic Lymphohistiocytosis, is due to decreased Natural Killer cell activity, resulting in increased activation of other T cell subtypes and production of cytokines. We present four cases of HSC managed at our center between October 2008 \& February 2010.
\end{abstract}

Key words: Histiocytosis Syndromes of Childhood, Langerhan's cell Histiocytosis (LCH), Hemophagocytic Lymphohistiocytosis (HLH), Macrophage Activation Syndrome (MAS).

\section{Case Reports}

\section{Case 1: Case of Langerhans Cell Histiocytosis (LCH) - Class I Histiocytosis}

18 months male child, a case of myelosclerosis, on our follow up, blood transfusion dependent, presented with pallor, petechae, splenomegaly, and a non tender, non pulsatile swelling on the lateral side of right leg.

Investigations revealed $\mathrm{Hb}-11.8 \mathrm{~g} \%$, TLC-8400/ $\mathrm{cmm}$, Peripheral Blood Smear showed dimorphic anemia. Roentgenogram right lower limb showed a lytic lesion at the upper diaphyseal region of right fibula, which was suggestive of osteomyelitis or a malignant lesion. True cut biopsy of this lesion revealed the presence of giant cells. Bone scan was suggestive of primary bone tumor in right fibula with secondary metastasis in the skull, ribs and left tibia. Subsequently child developed pain over the lumbar region and had difficulty in sitting up. On neurological examination, there was no deficit in the limbs however there was truncal weakness. $X$ ray of Lumbo-sacral spine revealed collapse of D11, L3 and L5 vertebrae. True cut biopsy from the lesion in the frontal region of skull was diagnostic of Langerhan's Cell Histiocytosis.

Child was on chemotherapy with Etoposide, Vinblastin, 6Mercaptopurine and Prednisolone. Presently he is thriving well, asymptomatic; the swelling over the right leg has regressed, however is transfusion dependent.

Cases 2 and 3: Two cases of Hemophagocytic Lymphohistiocytosis (HLH) - Class II Histiocytosis

A nine year male child, a case of systemic onset juvenile rheumatoid arthritis since seven years of age, on OPD follow up, presented with short febrile episode of 10 
days, in October 2008. Examination revealed ill looking, febrile, pale child with moderate hepatosplenomegaly, firm in consistency with no systemic localization or joint involvement.

On investigations his $\mathrm{Hb}$ was $7.6 \mathrm{~g} \%$, TLC $4800 / \mathrm{cmm}$ and platelet $66,000 / \mathrm{cmm}$. Urine examination showed numerous pus cells and culture grew $E$ coli. As his clinical features and total counts were not commensurating with the severity of infection, a bone marrow examination was carried out which revealed histiocytes (6\%) and majority of them showed phagocytosis of nucleated RBC, myeloid precursors and platelets. Serum LDH (1667 IU/l), Ferritin (318 mcg/ml), Triglycerides were elevated $(402 \mathrm{mg} / \mathrm{dl})$ and there was hypofibrinogenemia (92 $\mathrm{mg} / \mathrm{dl}$ ), fulfilling the criteria by FHL study group of the Histiocyte society for diagnosis of $\mathrm{HLH}$.

He was diagnosed as a case of Macrophage Activation Syndrome and was administered appropriate antibiotics for his UTI along with cyclosporine, methylprednisolone and other supportive measures. He is presently on our follow up and is asymptomatic.

\section{Case 3}

Ten year male child presented with fever off and on of four years duration, abdominal distention, pallor, and jaundice of two weeks. In view of chronic febrile waxing and waning illness of four years, a differential diagnosis of tuberculosis was considered elsewhere and Anti Tb Treatment (ATT) was started. Patient was non-compliant to treatment and ATT was discontinued after two months without medical advice. On examination he was thinly built, wasted, febrile, severely icteric with mild pallor, minimal pedal oedema, significant cervical lymphadenopathy, ascites and a non tender hepatomegaly of $4 \mathrm{~cm}$, which was firm to hard in consistency with well defined edges and splenomegaly of $9 \mathrm{cms}$.

His blood investigations revealed Pancytopenia (Hb-4.3 gm \%,TLC 3,400/cmm, Platelet 57 000/cmm), S.bilirubin $41 \mathrm{mg} / \mathrm{dl}$, SGOT - $443 \mathrm{IU} / \mathrm{L}$, SGPT- $269 \mathrm{IU} /$ L, ALP- 338 IU/I, LDH-384 IU/l, Total protein- 6.2mg/ dl, S.Ferritin- $451.2 \mathrm{mcg} / \mathrm{ml}$, Triglyceride-359 mg/dl, S.Fibrinogen $359 \mathrm{mg} / \mathrm{dl}$, Viral markers for hepatitis were negative. Ultrasound Abdomen showed hepatomegaly (16 cms), splenomegaly $(17 \mathrm{cms})$ and ascites, no features of portal hypertension. There were multiple retroperitonial and mediastinal lymph nodes. Findings were confirmed in CT abdomen. Laparoscopic lymph node biopsy revealed no features of tuberculosis or lymphoma. Bone marrow biopsy was suggestive of Haemophagocytosis.
Child was managed as a case of acute hepatitis on an underlying undiagnosed chronic disease and HLH. Child improved over a period of one and half months of inpatient treatment at our PICU. Repeat bone marrow and lymph node biopsy after aggressive management of HLH revealed Hodgkin's Lymphoma and he is responding well to chemotherapy. HLH was secondary to underlying malignancy.

\section{Case 4: A Case of Class III Histiocytosis- Malignant histiocytosis}

A three years age male child, presented with fever with rashes off and on, increasing pallor and distension of abdomen for 6 months, clinically he was irritable, pale, petechae, generalized lymphadenopathy and moderate hepatosplenomegaly.

His Investigations showed $\mathrm{Hb} 6.8 \mathrm{~g} \%$, Platelet of $24,000 / \mathrm{cmm}$ and TLC 15,000/cmm, DLC- P $30 \%$, L $60 \%$.Peripheral Blood Smear was suggestive of Acute Leukemia (Subleukemic phase) with 10\% blasts, myelocytes - 05\% band Forms \& metamyelocytes$10 \%$. Bone marrow revealed florid hemophagocytosis suggestive of $\mathrm{HLH}$.

Child was started on Tab Dexamethasone, Cyclosporine, Dapsone, and empirically on Acyclovir with broad-spectrum antibiotics with a working diagnosis of infection associated $\mathrm{HLH}$, to which he showed transient improvement.

However, repeat bone marrow after four weeks showed features consistent with acute monocytic leukemia $A M L-M 5$, confirmed by immunophenotyping as AML-M4. Inspite of our best efforts we were not able to save the child.

\section{Discussion}

Childhood histiocytosis are a group of rare and potentially fatal disorders characterized by overwhelming activation of normal $\mathrm{T}$ cells and macrophages which can cause clinical and hematological alterations. Based on histiopathological findings three classes of child hood histiocytosis are recognized ${ }^{1}$. Class I histiocytosis or $\mathrm{LCH}$, Class II or HLH and unequivocal malignancies of monocyte macrophage lineage are categorized to Class III. The incidence of Langerhan's cell Histiocytosis is reported to be 10 case per 2 million population as a whole $^{2}$ and annual incidence of Hemophagocytic Lymphohistiocytosis ( $\mathrm{HLH}$ ) to be 1.2 cases per $10,00,000$ children under the age of 15 years. 


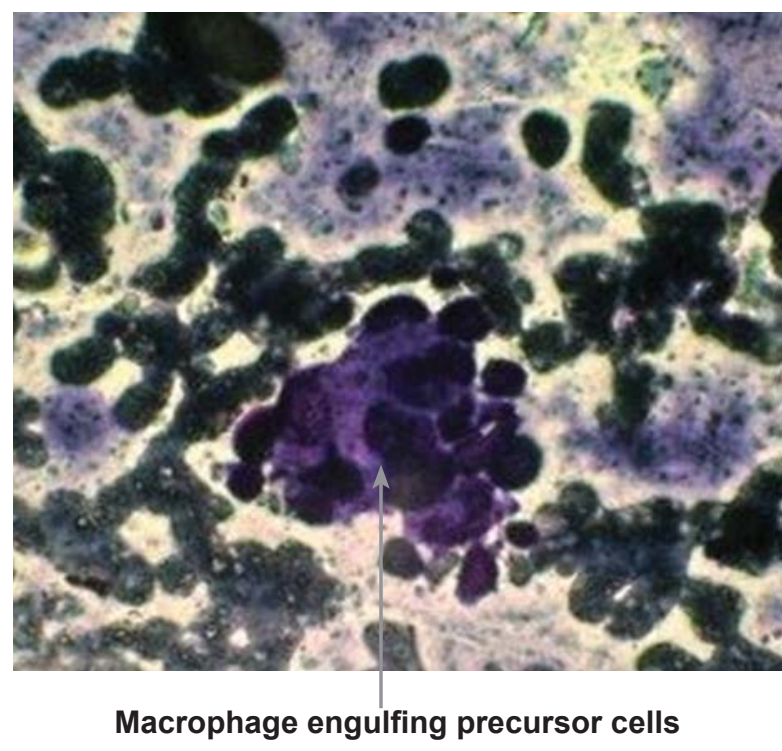

Fig 1: Photomicrograph of bone marrow aspiration stained with leishmania giemsa stain showing a macrophage engulfing precursor cells.

$\mathrm{LCH}$ encompasses three syndromes HandSchuller-Christian disease, Letterer-Siwe disease, and eosinophilic granuloma, although of historical importance, have no pathologic basis. $\mathrm{LCH}$ can involve any part of the body, but bone is the most frequent site. The characteristic finding is the clonal proliferation of cells of monocyte lineage containing tennis racquet shaped Birbeck granules,expressing a newly characterized antigen, langerin ( CD207) 1 .

Class I histiocytoisis is characterized by prominence of Langherhans' cells, Class II is due to non malignant proliferation and uncontrolled hemophagocytosis by macrophages in bone marrow. The term hemophagocytosis means the pathologic finding of macrophages, engulfing RBC, WBC, platelets, and their precursors. This is the most important finding in patients with hemophagocytic syndrome, and now renamed as Hemophagocytic Lymphohistiocytosis (HLH). The diagnosis of $\mathrm{HLH}$ is essentially made on the criteria by FHL study group of the Histiocyte society ${ }^{1,3,4}$.

The exact pathophysiology of $\mathrm{HLH}$ is yet to be determined. Current evidences are that its due to decreased NK cell activity resulting in increased $T$ cell activation and thus production of large quantity of cytokines like TNF-alpha and IFN- $\gamma^{5,6,7}$. The is also an increase in plasma concentration of soluble interleukin 2 (IL-2) receptor (sCD25) 1,5 , The elevated levels of ferritin and SCD25 receptor have catastrophic outcome. Low ferritin levels does not rule out HLH as it may be due to ferritin measurements some time after the peak of macrophage activation as reflected in our cases ${ }^{3}$.
HSC requires high index of suspicion for early diagnosis of the disease; the precipitating cause of $\mathrm{HLH}$ was Stills disease in second case, while it was an underlying malignancy in third and fourth cases. The term Macrophage activation syndrome is almost synonymous with Hemophagocytic Lymphohistiocytosis ${ }^{3}$. The peculiarity of the fourth case was that, the malignancy remained masked till late as the blasts were actively phagocytosed by histiocytes in the bone marrow. AML was diagnosed in bone marrow only after aggressive treatment of $\mathrm{HLH}$ and when the phagocytotic activity came down.

These being rare disorders and in the absence of well-controlled trials; CyclosporinA, IVIG, Corticosteroids, TNF blockade and Etoposide are used for treatment with varied success. Standard care for primary HLH is the $\mathrm{HLH}$ protocol of $2004^{8}$. Many of the drugs we use and the regime we follow is similar to this protocol. There are recent reports suggesting Etanercept and anakinara (IL1RA) as useful adjunctive therapeutic agents ${ }^{9,10}$.

This case series are presented to sensitize pediatricians about the clinical entity of HSC, to be suspected when children present to them with bonylesions or fever unresponsive to antibiotics with pancytopenia of unknown origin and hepatosplenomegaly.

\section{References}

1. Ladisch S. Histiocytosis syndromes of childhood. In: Kliegman RM, Behrman RE, Jenson HB, Stanton BF (eds.). Nelson Textbook of Pediatrics. $18^{\text {th }}$ ed. Philadelphia: Elsevier; 2008; 2:2159-61.

2. Dayananda L, Moorthy S, Prabhu NK, Sreekumar KP, Ghongade DV. Pulmonary langerhan's cell histiocytosis $\mathrm{X}$ : A case report. Indian J Radiol Imaging 2003; 13(3):275-6.

3. Kumar MK, Suresh MK, Dalus D. Macrophage Activation Syndrome. J Assoc Physicians India 2006;54:238-40.

4. Henter JI, Elinder G, Ost A. Diagnostic guidelines for hemophagocytic lymphohistiocytosis. The FHL Study Group of the Histiocyte Society. Semin Oncol 1991;18:29-33.

5. AricoM,DanesinoC,PendeD,MorettaL.Pathogenesis of haemophagocytic lymphohistiocytosis. $\mathrm{Br} J$ Haematol 2001;114:761-9.

6. Kotwal J, Shanmuganandan K, Macrophage activation syndrome: I/II, Indian Journal of Rheumatology 2009;4; 112-8. 
7. Muta T, Yamano Y. Fulminant hemophagocytic syndrome with a high interferon gamma level diagnosed as macrophage activation syndrome. Int J Hematol 2004;79:484-7.

8. Henter JI, Horne A, Arico' M, Egeler RM, Filiporich AH, Imashuku S, Ladisch S, McClain K, Webb D, Winiarski J, Janka G. HLH-2004: Diagnostic and Therapeutic Guidelines for Hemophagocytic Lymphohistiocytosis. Pediatr Blood Cancer 2007; 48: 124-31.
9. Makay B, Yilmaz S, Türkyilmaz Z, Unal N, Oren $H$, Unsal E. Etanercept for therapy-resistant macrophage activation syndrome. Pediatr Blood Cancer 2008;50(2): 419-21.

10. Kelly A, Ramanan AV. A case of macrophage activation syndrome successfully treated with anakinra. Nat Clin Pract Rheumatol 2008; 4: 61520.

\section{How to cite this article?}

Ramesh M, Singh V, Ghuliani R, Kapur BN, Singh J, Shankar S. Histiocytosis Syndromes of Childhood: A report of four cases. J Nep Paedtr Soc 2010;30:171-174. 